\title{
HSCs-derived COMP drives hepatocellular carcinoma progression by activating MEK/ ERK and PI3K/AKT signaling pathways
}

Qing Li, Cong Wang, Yufeng Wang, Liankang Sun, Zhikui Liu, Liang Wang, Tao Song, Yingmin Yao, Qingguang Liu* and Kangsheng Tu*

\begin{abstract}
Background: Cartilage oligomeric matrix protein (COMP) is known to promote fibrosis in skin, lung and liver. Emerging evidence shows that COMP plays critical roles in tumor development, including breast cancer, colon cancer and hepatocellular carcinoma (HCC). Nevertheless, the role of COMP in HCC proliferation and metastasis and its underlying mechanisms remain fully unclear.
\end{abstract}

Methods: Serum COMP was determined by ELISA. Cell Counting Kit-8 and plate colony formation were performed to evaluate cell proliferation. Wound healing and transwell assays were used to determine migration and invasion of HCC cells. Western blotting and immunofluorescence were carried out for detection of epithelial-to-mesenchymal transition (EMT) markers and MMPs in HCC cells. The in vivo role of COMP was evaluated using mouse models. We also measured effects of hepatic stellate cells (HSCs)-conditioned medium (CM) on HCC progression using transwell coculture system.

Results: Here, we found that serum COMP levels in HCC patients were significantly higher than those in healthy controls. Accordingly, high serum COMP levels in HCC patients significantly correlated with malignant clinical characteristics and poor clinical outcomes. Next, we investigated that recombinant human COMP protein (rCOMP) treatment resulted in increased abilities of proliferation, invasion and migration of HCC cells. Furthermore, rCOMP treatment enhanced proliferative and metastatic colonization of HCC cells in vivo. Mechanistically, CD36 receptor played an essential role in COMP-mediated HCC cell proliferation and metastasis. Functionally, COMP/CD36 signaling caused phosphorylation of ERK and AKT, resulting in the upregulation of tumor-progressive genes such as EMT markers, MMP-2/9, Slug and Twist in HCC cells. Interestingly, we revealed that COMP was secreted by HSCs. CM of LX2 cells with COMP knockdown showed weaker effects on the activation of MEK/ERK and PI3K/AKT signaling pathways in HCC cells compared to control CM.

Conclusions: Our findings indicated that HSCs-derived COMP collaborated with CD36 and subsequently played an essential role in MEK/ERK and PI3K AKT-mediated HCC progression. COMP might act as a promising target for the diagnosis and treatment of aggressive HCC.

Keywords: Hepatocellular carcinoma, Microenvironment, Hepatic stellate cells, COMP, Tumor progression

\footnotetext{
* Correspondence: liuqingguang@vip.sina.com; tks0912@foxmail.com Department of Hepatobiliary Surgery, the First Affiliated Hospital of Xi'an Jiaotong University, 277 Yanta West Road, Xi'an 710061, Shaanxi Province, China
}

(c) The Author(s). 2018 Open Access This article is distributed under the terms of the Creative Commons Attribution 4.0 International License (http://creativecommons.org/licenses/by/4.0/), which permits unrestricted use, distribution, and reproduction in any medium, provided you give appropriate credit to the original author(s) and the source, provide a link to the Creative Commons license, and indicate if changes were made. The Creative Commons Public Domain Dedication waiver (http://creativecommons.org/publicdomain/zero/1.0/) applies to the data made available in this article, unless otherwise stated. 


\section{Background}

Hepatocellular carcinoma ( $\mathrm{HCC}$ ) is the most common malignancies worldwide with a third rank of mortality rate in all types of cancer [1]. HBV or HCV, exposure to alcohol intoxication are major risk factors which induced hepatic inflammation and fibrosis and consequently lead to cirrhosis as observed in $80 \%$ of HCC patients [2]. Elucidating the molecular signaling mechanisms of cirrhosis to HCC and the search for the novel therapeutic targets and treatment are of great significance in improving the overall prognosis of HCC patients.

Cartilage oligomeric matrix protein (COMP), a cartilage metabolism marker, is an extracellular matrix protein that modulates the cellular phenotype during tissue genesis and remodeling. Recently, it has been extensively studied for its pro-fibrosis potential against various internal organs, for instance, pulmonary fibrosis [3], and liver cirrhosis [4]. Earlier work has suggested that COMP levels in the serum of HCC patients and HCC tissues are abnormally elevated compared with healthy controls and it can be used as diagnostically in the non-invasive estimation of liver cirrhosis and HCC development $[5,6]$. Recent studies have shown that COMP promotes the progression of breast cancer, colon cancer and prostate cancer [7-9]. These results suggest that COMP may be an important pro-HCC molecule, but the mechanism by which COMP plays a role in HCC still needs to be further studied.

CD36 is a traditional membrane receptor of the thrombospondin family that binds to CD36 thereby activating downstream signaling pathways involved in various cellular processes. In HCC, CD36 is abnormally high which promotes EMT process by increasing free fatty acid uptake $[10,11]$. Increasing evidences indicate that EMT contributes to tumor metastasis and chemotherapy resistance of HCC [12-16]. Transcriptional repressors of epithelial gene such as Snail, Slug and Twist are essentially involved in EMT and either directly or indirectly induced by signaling from MEK/ERK or PI3K/AKT [17]. Recent studies have found that COMP binds to CD36 and activates downstream signaling pathways and ultimately leading to the progression of liver cirrhosis $[4,18]$.

In the present study, we specifically investigated the effect of COMP on the malignant behaviors of HCC by in vivo and in vitro experiments, including proliferation, migration and invasion. Notably, we discovered that activated hepatic stellate cells (HSCs)-derived COMP regulated mesenchymal gene expression and MMPs in HCC cells via CD36 and caused aberrant phosphorylation of ERK and AKT. Analysis of primary HCC serum samples supported the predictive role of COMP in patient's survival, suggesting that COMP was a promising biomarker and an effective bioactive strategy to combat tumor-progression.

\section{Methods}

\section{Cell culture and treatment}

The HCC cell lines (MHCC-97H, HepG2, Huh7, Hep-3B, SMMC-7721) and the immortalized human liver cell line LO2 and activated hepatic stellate cells (HSCs) LX2 were purchased from the Shanghai cell bank (Shanghai Institute for Biological Science, Chinese Academy of Science, Shanghai, China) and cultured at $37{ }^{\circ} \mathrm{C}$ in a humidified atmosphere with $5 \% \mathrm{CO}_{2}$ in high-glucose Dulbecco's Modified Eagle's Medium (DMEM; Invitrogen, NY, USA) supplemented with $10 \%$ fetal bovine serum (FBS; Hyclone, Logan, UT, USA) and $1 \%$ penicillin-streptomycin. The culture medium was replaced with serum-free DMEM $12 \mathrm{~h}$ before treatment with $0-5 \mu \mathrm{g} / \mathrm{ml}$ of human rCOMP (R\&D Systems, Minneapolis, MN) according to the manufacture's recommendations.

\section{Clinical samples and ELISA}

Venous blood samples of 100 HCC patients without other complications (before the surgery) and 30 healthy volunteers were obtained from the First Affiliated Hospital of Xi'an Jiaotong University between 2015 and 2017, the serum was obtained after centrifugation at 3, $000 \mathrm{rpm}$ for $15 \mathrm{~min}$ and stored at $-80{ }^{\circ} \mathrm{C}$. Ethic permission was obtained from the Ethics Committee of the First Affiliated Hospital of Xi'an Jiaotong University. Written informed consent was obtained from each patient or family members.

Quantitative measurement of human COMP in serum of HCC patients were performed by human COMP ELISA kit (R\&D System, Minneapolis, MN) following the manufacturer's protocols. Briefly, serum of HCC patients was collected before the surgery, cell supernatants were collected after cultivated in serum-free medium for $24 \mathrm{~h}$. A seven-point standard curve was generated for every plate and quantified using the GraphPad Prism 5.0 software (La Jolla, USA). All samples were analyzed in triplicates.

In vitro cell proliferation and plate colony-forming assays The cell proliferation was measured using the Cell Counting Kit-8 (CCK-8) (Dojindo, Kyushu, Japan). Cells were seeded in 96-well plates at $4 \times 10^{3}$ cells/well and incubated overnight to allow their adhesion to the plate. Cells were treated with rCOMP in different concentrations $(0,0.8,1,2$ and $5 \mu \mathrm{g} / \mathrm{ml})$ for $12 \mathrm{~h}, 24 \mathrm{~h}$, and $36 \mathrm{~h}$, five parallel wells for each concentration. Ten microliters of CCK8 (Sigma-Aldrich, St. Louis, MO, USA) was added to 90ul of the medium per well and incubated at $37{ }^{\circ} \mathrm{C}$ for $4 \mathrm{~h}$. The absorbance was detected at $450 \mathrm{~nm}$ with microplate autoreader (Bio-Rad, CA, USA).

For the colony formation assay, Hep-3B and SMMC7721 cells in exponential growth phase were seeded into 6-well plates at a density of 1000 cells/well. After overnight 
incubation, cells were treated with $\operatorname{rCOMP}(0,1,2$ and $5 \mu \mathrm{g} / \mathrm{ml}$ ) and maintained in culture medium for 2 weeks and the medium with corresponding rCOMP concentrations was replaced every three days. The colonies were fixed with $4 \%$ methanol and stained with $0.1 \%$ crystal violet at room temperature and the number of colonies was counted. Data were collected from three independent experiments.

\section{Wound-healing assay and Transwell migration and invasion assays}

The cells were grown to a $90-100 \%$ confluence cell monolayer overnight prior to serum starvation for $8 \mathrm{~h}$ in 6-well plates. After wounding with a sterile pipette tip, cells were then washed with PBS to eliminate the floating cells. Cells were treated with $\operatorname{rCOMP}(0,1,2$ and $5 \mu \mathrm{g} / \mathrm{ml}$ ) and the wounds were photographed at time $0 \mathrm{~h}$ and $24 \mathrm{~h}$ post-wounding under a phase-contrast microscope. Cell migration was quantitated by measuring the width of the wounds. Migration rate was calculated as $(\%)=[\mathrm{W}(24 \mathrm{~h})-\mathrm{W}(0 \mathrm{~h})] / \mathrm{W}(0 \mathrm{~h})$. Experiments were performed with at least three times.

The migration assay was performed in a Transwell chemotaxis 24-well chamber (BD Biosciences, Franklin Lakes, NJ), $2 \times 10^{4}$ cells in $200 \mu \mathrm{l}$ serum-free medium were plated in the upper chambers. For invasion assay, the basement membrane of filters was coated with $50 \mu \mathrm{l}$ Matrigel (Matrigel; BD Biosciences, Bedford, MA). After incubation with $\operatorname{rCOMP}(0,1,2$ and $5 \mu \mathrm{g} / \mathrm{ml})$ for $24 \mathrm{~h}$, cells migrated or invaded to the lower surface of the membrane were stained with crystal violet. The result was determined by counting the stained cells using optical microscopy $(200 \times$ magnifications $)$ in five randomly selected fields. Each experiment was carried out in triplicate wells and repeated at least three times.

\section{Western blot analysis}

Western blot analysis was performed to detected the levels of COMP (ab11056, Abcam, Cambridge, UK), CD36 (ab133625, Abcam), E-cadherin (3195, Cell Signaling Technology, Danvers, USA), N-cadherin (14,215, Cell Signaling Technology), Vimentin (5741, Cell Signaling Technology), MMP-2 (13,132, Cell Signaling Technology), MMP-9 (sc-393,859, SANTA CRUZ), Snail (ab167609, Abcam), Slug (9585, Cell Signaling Technology), Twist (ab175430, Abcam), AKT (4691, Cell Signaling Technology), P-AKT (Thr308) (13,038, Cell Signaling Technology), ERK (5013, Cell Signaling Technology), P-ERK (4370, Cell Signaling Technology), ki-67 (ab15580, Abcam), $\alpha$-SMA (ab5694, Abcam), $\beta$-actin (sc-47,778, SANTA CRUZ). Cells treated with $\operatorname{rCOMP}(0,1,2$ and $5 \mu \mathrm{g} / \mathrm{ml}$ ) were planted in 6 -well plates for $24 \mathrm{~h}$ or $48 \mathrm{~h}$, and lysed in lysis buffer (Invitrogen). Protein concentration was determined by the BCA Kit (Pierce, IL, USA) and $40 \mu \mathrm{g}$ of each samples was separated by sodium dodecyl sulfate-polyacrylamide gel electrophoresis (SDSPAGE) and transferred to polyvinylidene difluoride (PVDF) membranes (Millipore, Bedford, MA, USA). After incubated with primary antibodies overnight at $4{ }^{\circ} \mathrm{C}$, the membranes were then incubated with the appropriate HRP-conjugated secondary antibody for $1 \mathrm{~h}$ at room temperature and visualized using the Bio-Rad Gel imaging system and analyzed by the software program as specified by Bio-Rad.

\section{Immunohistochemical analysis (IHC) and immunofluorescence} (IF) analysis

The tumor tissue sections embedded in paraffin were incubated with ki-67 (1:200), CD36 (1:200), CD36 (1:200), E-cadherin (1:200), N-cadherin (1:200) and Vimentin (1:200) antibodies.

For immunofluorescence staining, treated cells were stained with E-cadherin (1:100; Cell Signaling Technology), Vimentin (1:100; Cell Signaling Technology) overnight at $4{ }^{\circ} \mathrm{C}$, followed by incubation with corresponding FITC-conjugated secondary antibody (Invitrogen) for $1 \mathrm{~h}$ at room temperature. Cells were quantified by confocal immunofluorescence microscopy (Zeiss, Oberkochen, Germany).

\section{Cell transfections}

For CD36 stable knockdown assay, lentiviral containing short hairpin RNAs specially targeting CD36 (shCD36, sense: 5'-GUACCCUGUUACUACCACAdTdT-3', antisense: 5'-UGUGGUAGUAACAGGGUACdTdT-3') and the scramble control short hairpin RNA (shCtl) cloned were purchased from GeneChem Corporation (Shanghai, China) and transfected into SMMC-7721 cells using Lipofectamine 2000 according to the manufacturer's instructions. Experiments were conducted $48 \mathrm{~h}$ and knockdown efficiency was verified by Western blot.

For COMP knockdown assay in LX2 cells, small interfering RNA (siRNA) specific to COMP (siRNA1: sense: 5'-AGAAACUUGAGCUGUUGAUGCC-3', antisense: 5'-GGCUAUCAAGACAGCUCAAGUUUCU-3'; siRNA2: sense: 5'-GAGACAAGATCGACGTGTGTC-3', antisense: 5'-GACACACGTCGATCTTGTCTC-3') and the scramble siRNA (NC siRNA) were purchased from Biomics Biotechnologies (Guangzhou, PR China). The cells were plated into 6-well plates and then transfected with $100 \mathrm{nM}$ siRNA using Lipofectamine 2000 (Invitrogen, Eugene, OR, USA) according to the manufacturer's instructions. Cells were collected for further investigation at the indicated hours after transfection.

\section{Animal experiments}

All animal experiments were conducted in compliance with ethical regulations and approved by the ethical 
committee of animal care of the Xian Jiaotong University, Xi'an, China. For the in vivo tumor formation, 10 female BALB/C nude mice aged 4 weeks (Shanghai SLAC Laboratory Animal Center of Chinese Academy of Sciences, Shanghai, China) were used to establish subcutaneous tumor model. $1 \times 10^{6}$ SMMC-7721 cells, which were used in our in vitro experiments, were suspended in $100 \mu \mathrm{l}$ PBS and incubated with $\mathrm{rCOMP}(2 \mu \mathrm{g} / \mathrm{ml})$ at $37^{\circ} \mathrm{C}$ for $2 \mathrm{~h}$ prior to injection. Then SMMC-7721/rCOMP and SMMC-7721/PBS were subcutaneously injected into the left and right (control) flanks of mice. Tumor growth was monitored by estimating the tumor volume by the formula " $\mathrm{a} / 2 \times \mathrm{b}^{2}$ ", in which a and $\mathrm{b}$ represents the largest and smallest diameters, respectively. The mice were sacrificed at day 7. This animal model was applied in our previous publication [19].

For the effect of COMP on pulmonary metastasis was examined by intravenous tail veil injections experiment of $1 \times 10^{6}$ SMMC-7721 cells with or without $2 \mathrm{~h}$ rCOMP pre-incubation. In addition, experimental animals ( $n=6 /$ group) received either $\mathrm{rCOMP}(1 \mathrm{mg} / \mathrm{kg} / \mathrm{d})$ or PBS 3 times per week by tail vein injections. The dose was calculated based on the cutoff value of COMP level in human [20]. The mice were sacrificed 4 weeks and the lung metastases were confirmed by H\&E staining.

For assessment of the function of CD36 in vivo, an orthotopic liver tumor model in nude mice was established. Briefly, $1 \times 10^{6}$ SMMC-7721-shCD36 and SMMC-7721-shCtl cells ( $n=5 /$ group) were suspended in 100ul PBS and incubated with rCOMP for $2 \mathrm{~h}$ subcutaneously injected into nude mice liver as described [21]. Subsequently, these mice were injected with $\mathrm{rCOMP}$ at doses of $1 \mathrm{mg} / \mathrm{kg} / \mathrm{d}$ or PBS through tail vein, 3 times per week for the duration of the experiment. After 4 weeks the livers and lungs were collected and prepared for further analysis.

\section{Transwell coculture system}

Hep-3B or SMMC-7721/LX2 cocultures were conducted in serum-free DMEM for $24 \mathrm{~h}$ using transwell inserts (6.5 $\mathrm{mm}$ diameter with polycarbonate membrane filters containing $0.4 \mu \mathrm{M}$ pores, Corning, NY) which allow diffusion of media components but prevent cell migration (Corning Inc., NY). HCC cells were collected for further investigation.

\section{Statistical analysis}

All the data were expressed as mean \pm standard deviation (SD) of 3 independent experiments. Prism 5 and SPSS 13.0 software were applied for all statistical analyses. Pearson chi-square test, ANOVA and Student's t-test were used for comparison between multiple or two groups. Kaplan-Meier method with Log-rank test were used for survival analysis. Univariable and multivariable survival analyses were performed by Cox proportional hazards regression model. ${ }^{*} P<0.05$ and ${ }^{* *} P<0.01$ were taken as indicative of statistically significant difference.

\section{Results}

Increased serum level of COMP is associated with poor clinicopathological features and clinical outcomes of HCC patients

Our ELISA data showed that the serum content of COMP in the $100 \mathrm{HCC}$ samples ranged from $41.9 \mathrm{ng} / \mathrm{ml}$ to $494.3 \mathrm{ng} / \mathrm{ml}$ with a median of $170.7 \mathrm{ng} / \mathrm{ml}$. While, serum COMP level ranged from $44.2 \mathrm{ng} / \mathrm{ml}$ to $270.3 \mathrm{ng} /$ $\mathrm{ml}$ with a median of $127.1 \mathrm{ng} / \mathrm{ml}$ in the 30 healthy controls, and a significant difference was observed between HCCs and healthy controls $(P=0.0115$, Fig. 1a). According to the Youden index of the ROC curves (Fig. 1b), $127.7 \mathrm{ng} / \mathrm{ml}$ was determined as a optimal cutoff value for the diagnostic value of serum COMP in HCC. Results indicated that serum COMP was significantly upregulated in $64.0 \%(64 / 100)$ of HCC patients compared with the healthy controls $(40.0 \%, 12 / 30, P=0.019)$.

Next, a clinicopathological association analysis in the 100 HCCs found that the high-level of serum COMP was closely associated with poor clinicopathological features, including cirrhosis $(P=0.013)$, vascular invasion $(P=0.031)$, large tumor size $(P=0.020)$ and tumor recurrence $(P=0.043$, Additional file 1: Table S1). Furthermore, Kaplan-Meier analysis showed that HCC patients with high serum COMP level had poorer overall survival rate (OS; Log-rank, 4.674; $P=0.0306$, Fig. 1c) and disease-free survival rate (DFS; Log-rank, 4.227; $P=0.0398$, Fig. 1d). Analyses using univariate Cox regression indicated that tumor size, cirrhosis, vascular invasion and high serum COMP level were all found to be significantly related with overall survival $(P<0.05$, Table 1$)$. Most importantly, multivariate Cox proportional hazard regression analysis found tumor size, vascular invasion, and serum COMP high-level to be independent prognostic factors for the overall survival of HCC patients $(P<0.05$, Table 1$)$. These results together underlined that elevated serum COMP level was closely correlated with HCC progression.

\section{COMP shows a strong oncogenic function}

To explore the exact biological function of COMP in HCC, Hep-3B and SMMC-7721 cells were treated with different concentrations of rCOMP $(0.8 \mu \mathrm{g} / \mathrm{ml}$ to $5 \mu \mathrm{g} / \mathrm{ml})$, the proliferation activity of HCC cells was evaluated by CCK8. The presence of rCOMP significantly promoted the proliferative activity of $\mathrm{HCC}$ cells in a dose-dependent manner and the promoting effect of rCOMP peaked at $2 \mu \mathrm{g} / \mathrm{ml}(P<0.05$, Fig. $2 \mathrm{a})$. We further examined the effect of rCOMP on the growth of HCC cells by using plate colony formation assay. Our data showed that the growth of rCOMP-treated cells was markedly enhanced in a dose-dependent manner, as compared with their respective 

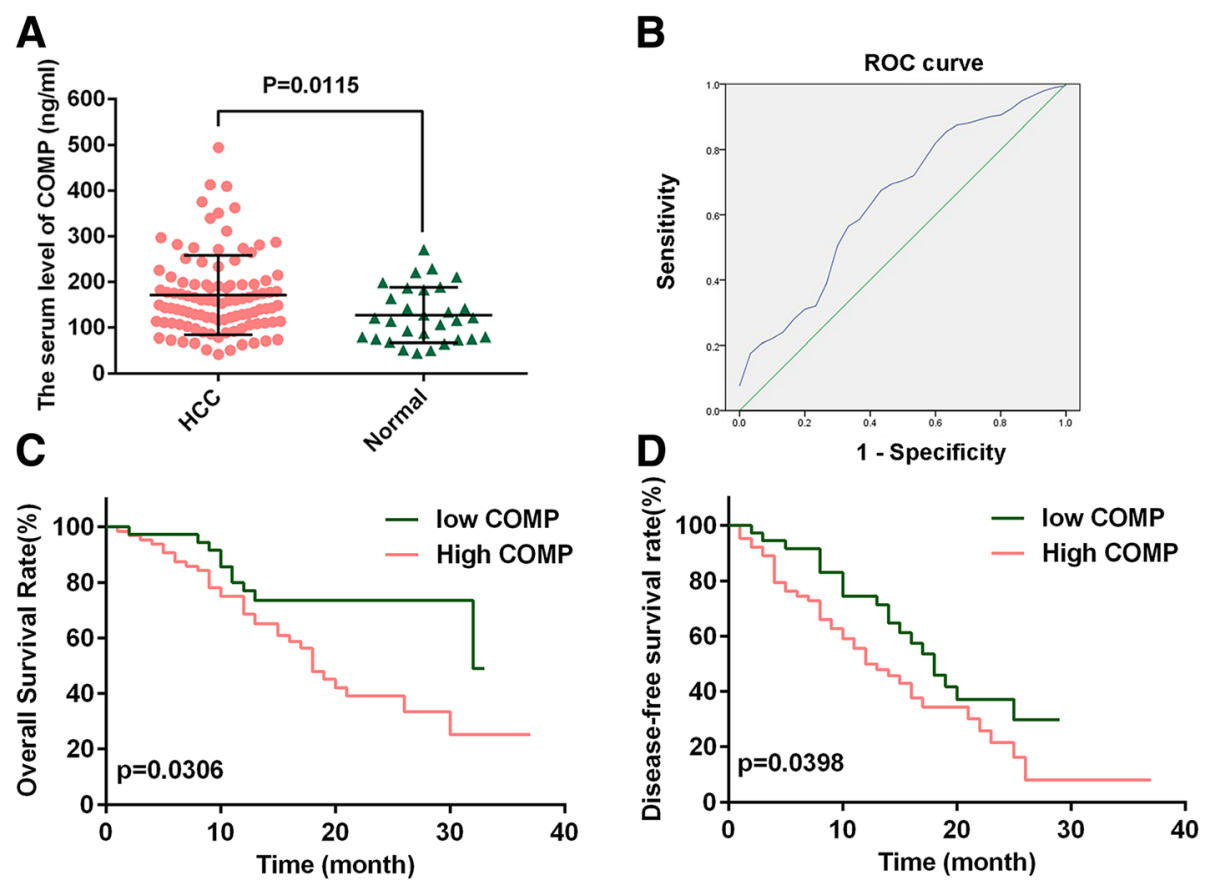

Fig. 1 COMP level is increased in the serum of HCC patients. a ELISA analysis of COMP serum level in 100 HCC patients and 30 healthy controls. $P=0.0115$ by t test versus normal controls. $\mathbf{b}$ ROC curve of serum COMP in 100 HCC patients and 30 normal controls. c and $\mathbf{d}$ The overall survival and disease-free survival of HCC patients with high or low level of COMP estimated using the Kaplan-Meier analysis and compared by the Log-rank test in the same set of patients

controls $(P<0.05$, Fig. $2 b)$. To test whether rCOMP treatment also participate in HCC growth in vivo, the subcutaneous tumor model in nude mice was established by subcutaneously implanting SMMC-7721 cells with or without rCOMP pre-incubation. Notably, in the subcutaneous tumor model, it was observed that the tumor volume was significantly higher in the rCOMP treated group compared to control group ( $P=0.0048$, Fig. 2c).
COMP enhances HCC cell invasion and tumor metastasis

Cancer progression is a multistep process that involves invasion of basement membrane by tumor cells and migration to points far from a given primary tumor mass, leading to metastasis [22]. Since COMP upregulation was significantly associated with HCC invasion, the role of COMP in tumor migration and invasion was further investigated. The wound healing assay showed that after

Table 1 Univariate and multivariate analysis of factors associated with overall survival in hepatocellular carcinoma patients

\begin{tabular}{|c|c|c|c|c|c|c|}
\hline \multirow[t]{2}{*}{ Features } & \multicolumn{3}{|c|}{ Univariate Analysis } & \multicolumn{3}{|c|}{ Multivariate Analysis } \\
\hline & $\mathrm{HR}$ & $95 \% \mathrm{Cl}$ & $P$ & $\mathrm{HR}$ & $95 \% \mathrm{Cl}$ & $P$ \\
\hline Age $(\leq 50$ versus $>50$ years $)$ & 0.446 & $0.158-1.370$ & 0.165 & & & \\
\hline Gender (Male versus Female) & 2.069 & $0.612-6.996$ & 0.242 & & & \\
\hline HBV (Negative versus Positive) & 0.377 & $0.103-1.379$ & 0.140 & & & \\
\hline Cirrhosis (Yes versus No) & 3.878 & $1.096-13.721$ & 0.036 & 2.750 & $0.980-7.716$ & 0.055 \\
\hline AFP (> 400 versus $\leq 400 \mathrm{ng} / \mathrm{mL}$ ) & 2.235 & $0.667-7.487$ & 0.192 & & & \\
\hline Vascular Invasion (Yes versus No) & 3.524 & $1.038-11.962$ & 0.043 & 3.408 & $1.159-10.026$ & 0.026 \\
\hline Tumor Size $(\leq 5$ versus $>5 \mathrm{~cm})$ & 0.120 & $0.028-0.512$ & 0.004 & 0.333 & $0.121-0.917$ & 0.033 \\
\hline Tumor encapsulation (Complete versus No/incomplete) & 0.363 & $0.121-1.092$ & 0.071 & & & \\
\hline Differentiation (poor versus Well/moderate) & 1.307 & $0.467-3.661$ & 0.611 & & & \\
\hline TNM stage (II/II versus I) & 1.546 & $0.456-5.235$ & 0.484 & & & \\
\hline COMP (high versus low) & 13.428 & $2.844-63.408$ & 0.001 & 6.574 & $2.154-20.061$ & 0.001 \\
\hline
\end{tabular}

HBV hepatitis B virus, AFP alpha-fetoprotein, TNM tumor-node-metastasis, HR hazard ratio, Cl confidence interval Significant values $(P<0.05)$ are in bold italic 

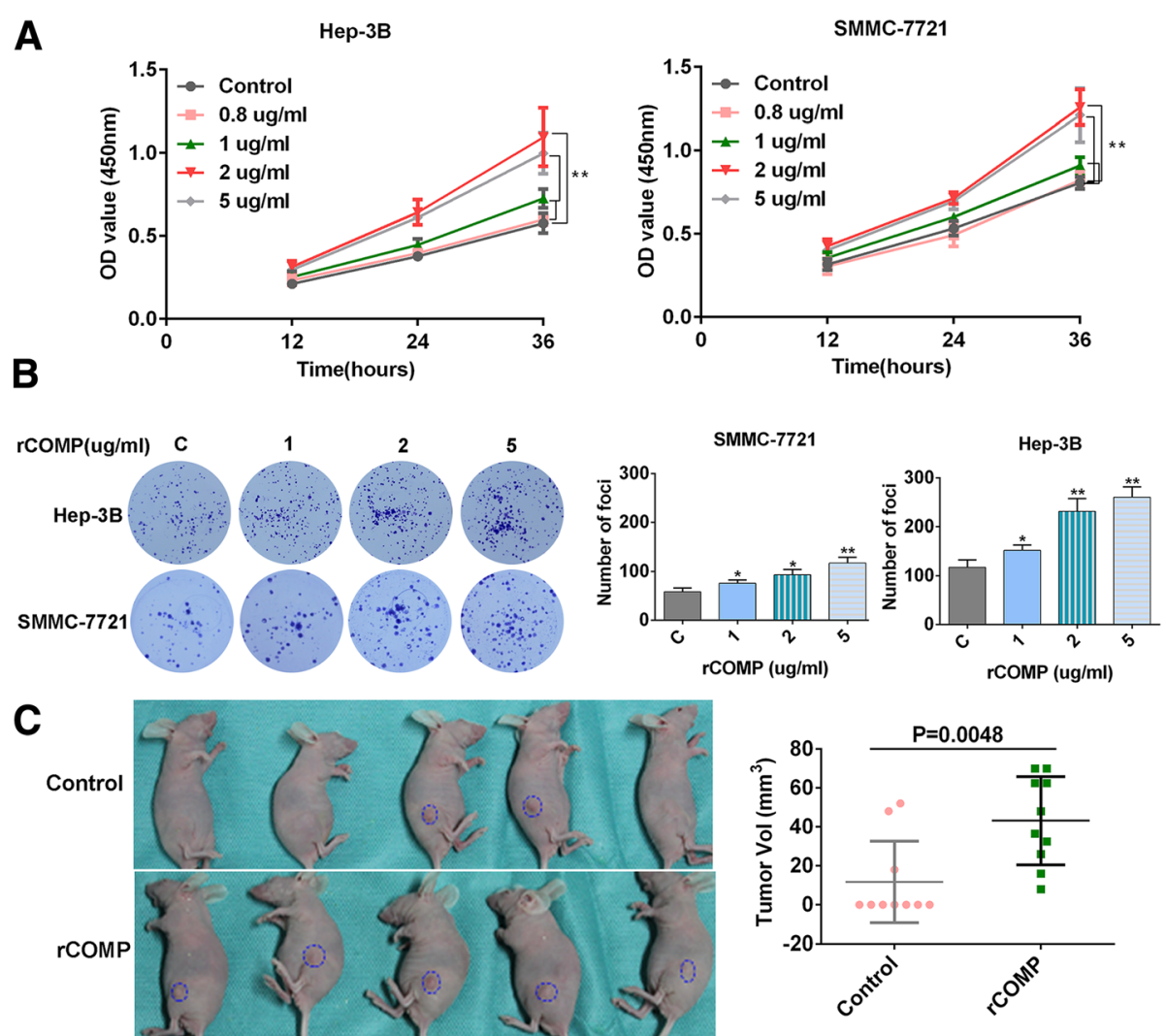

Fig. 2 COMP promotes the proliferation of HCC cells in vitro and in vivo. a HCC cells were treated with rCOMP at various concentrations (as indicated) and the cell viability were determined using CCK8 assay. The untreated cells was considered to be the control group. $n=$ three independent repeats. $P<0.05$ by ANOVA versus control. $\mathbf{b}$ Plate colony formation assay was used to confirm the growth promotional effect of rCOMP at various concentrations and the colony foci from three independent experiments were calculated and compared. $P<0.05$ by $t$ test versus control. c SMMC-7721 cells with rCOMP or PBS were subcutaneously injected into the mouse flanks to establish subcutaneous tumor models (10 mice each group). After treatments, all mice were observed and the tumor volume was measured and compared. Representative images at $\times 200$ magnification are shown. $P<0.05$ by t test versus control. $\left({ }^{*} P<0.05,{ }^{* *} P<0.01\right)$

incubation with $\mathrm{rCOMP}(1,2$, and $5 \mu \mathrm{g} / \mathrm{ml})$ for $24 \mathrm{~h}$, the migration distance of HCC cells were dose-dependently increased in comparison with untreated cells $(P<0.05$, Fig. 3a). As expected, transwell migration assay confirmed the positive effect of rCOMP on migration potential of HCC cells after rCOMP incubation $(P<0.05$, Fig. 3b). Next, as evident from Matrigel invasion assay, rCOMP treatment increased invasion of HCC cells through Matrigel in comparison with untreated cells $(P<0.05$, Fig. 3b). In summary, rCOMP at a concentration of $2 \mu \mathrm{g} / \mathrm{ml}$ significantly induced the metastasis potential of HCC cells. The effect of COMP on HCC invasive behavior was examined by injecting intravenously in the tail vein with SMMC-7721-rCOMP or SMMC-7721-PBS cells to mimic tumor metastasis. Notably, a significantly larger number of pulmonary metastatic nodules were induced in the SMMC-7721-rCOMP group than those in the control group $(P<0.01$, Fig. $3 c)$. On the whole, these in vitro and in vivo results verified that COMP enhanced metastasis dissemination of HCC.

\section{COMP promotes HCC metastasis by enhancing EMT and MMP-2/9}

Tumor cell migration and invasion are often associated with reorganization of the actin cytoskeleton and a phenomenon called EMT. Malignant hepatocytes that are transdifferentiated to a mesenchymal phenotype during EMT process can escape from tumor mass by individual cell movement. To investigate whether COMP-mediated promotion of metastasis occurs via the EMT process, we analyzed the expression levels of EMT markers and EMT-related transcription factors after exposure to rCOMP. As showed in Fig. 4a, rCOMP dose-dependently decreased the expression of epithelial marker (E-cadherin) and increased the expression of mesenchymal markers ( $\mathrm{N}$-cadherin and Vimentin) in Hep-3B and SMMC-7721 cells at 24 h, compared with respective controls. Interestingly, alteration of E-cadherin expression was accompanied by an opposite parallel regulation of EMT regulators Slug and Twist rather than Snail, suggesting that Slug and Twist may play an important role 


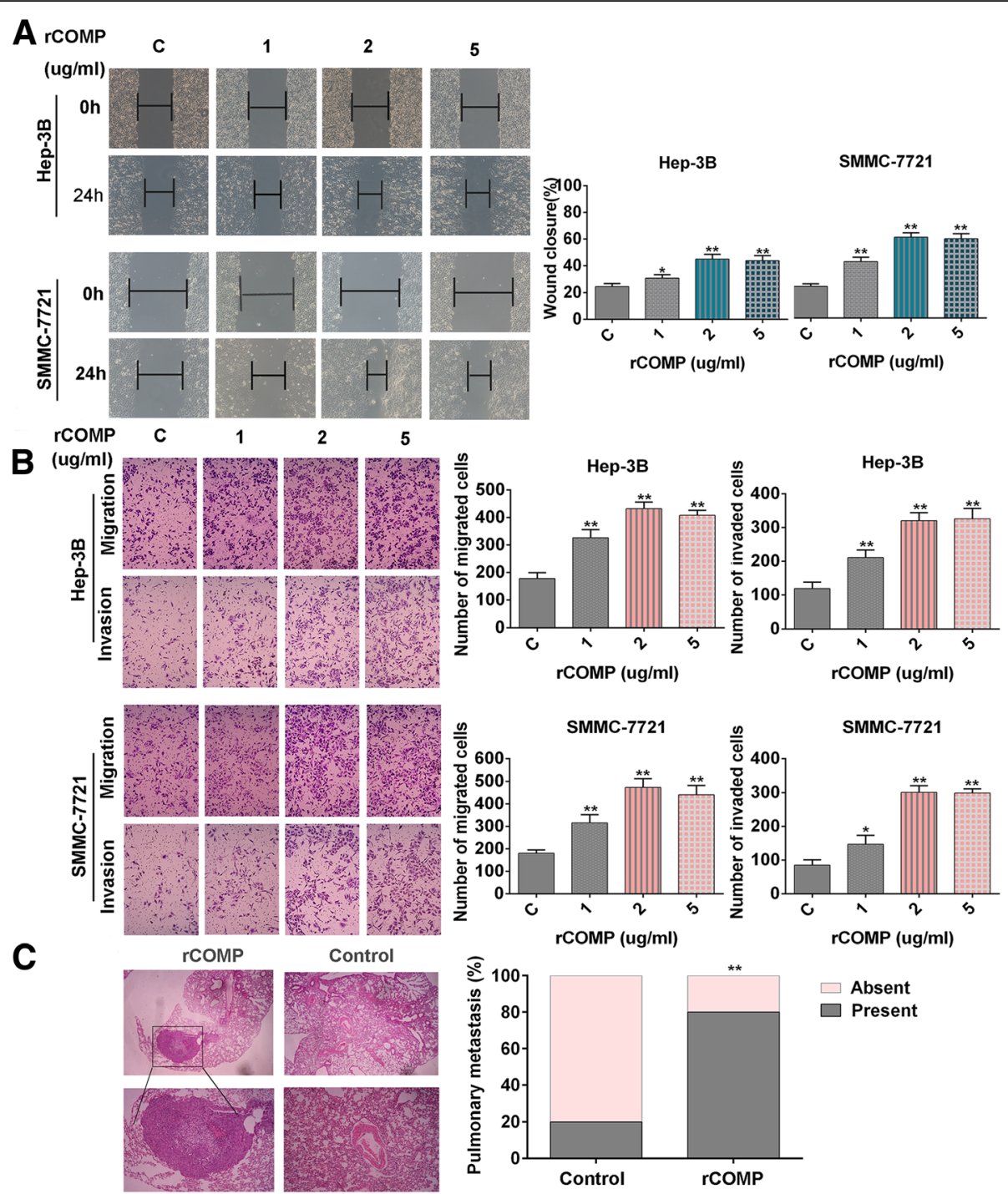

Fig. 3 COMP promotes HCC cell migration and invasion in vitro and in vivo. a Hep-3B and SMMC-7721 cells incubated with various concentrations of rCOMP (as indicated) for $24 \mathrm{~h}$ were subjected to wound-healing assay. Representative images at $\times 400$ magnification are shown. The wound closure (\%) of HCC cells in each concentration of rCOMP was calculated. $\mathrm{n}=$ three independent repeats. $P<0.05$ by $\mathrm{t}$ test versus control. $\mathbf{b}$ Transwell migration and invasion assays of HCC cells incubated with various concentrations of rCOMP (as indicated). The number of migrated or invaded cells was counted in five different fields. Representative images at $\times 200$ magnification are shown. $n=$ three independent repeats. $P<0.05$ by t test versus control. $\mathbf{c}$ Invasive behavior of HCC cells was examined by injecting intravenously in the tail vein with SMMC-7721-rCOMP $(n=6)$ or SMMC-7721-PBS (Control, $n=6)$ cells; Lung metastasis were counted by H\&E analysis. Representative images at $\times 200$ magnification are shown. $P<0.05$ by Pearson chi-square test versus control. $\left({ }^{*} P<0.05,{ }^{*} P<0.01\right)$

in COMP-mediated EMT (Fig. 4a and Additional file 2: Figure S1). The changes of EMT phenotype after rCOMP treatment were further confirmed by immunofluorescence (Fig. 4b). We also detected the expression of several matrix metalloproteinases (MMPs), which were known to participate in ECM remodeling, an essential part of tumor metastasis. After rCOMP treatment, MMP-2 and MMP-9 levels were significantly upregulated at $24 \mathrm{~h}$ in a dosedependent manner (Fig. 4c). These results were all typical of events that occur during EMT of tumor cells. In sum, these data further supported the efficacy of the rCOMP treatment in enhancing clonogenicity, migration and invasion of HCC cells.

\section{COMP activates the MEK/ERK and PI3K/AKT signaling pathways in HCC cells}

Activation of MEK/ERK and PI3K/AKT has been shown to regulate cancer cell migration and invasion through distinct pathways by promoting the transcription activation of various transcription factors and MMPs-mediated matrix degradation $[23,24]$. We examined whether rCOMP treatment affected MEK/ERK and PI3K/AKT 


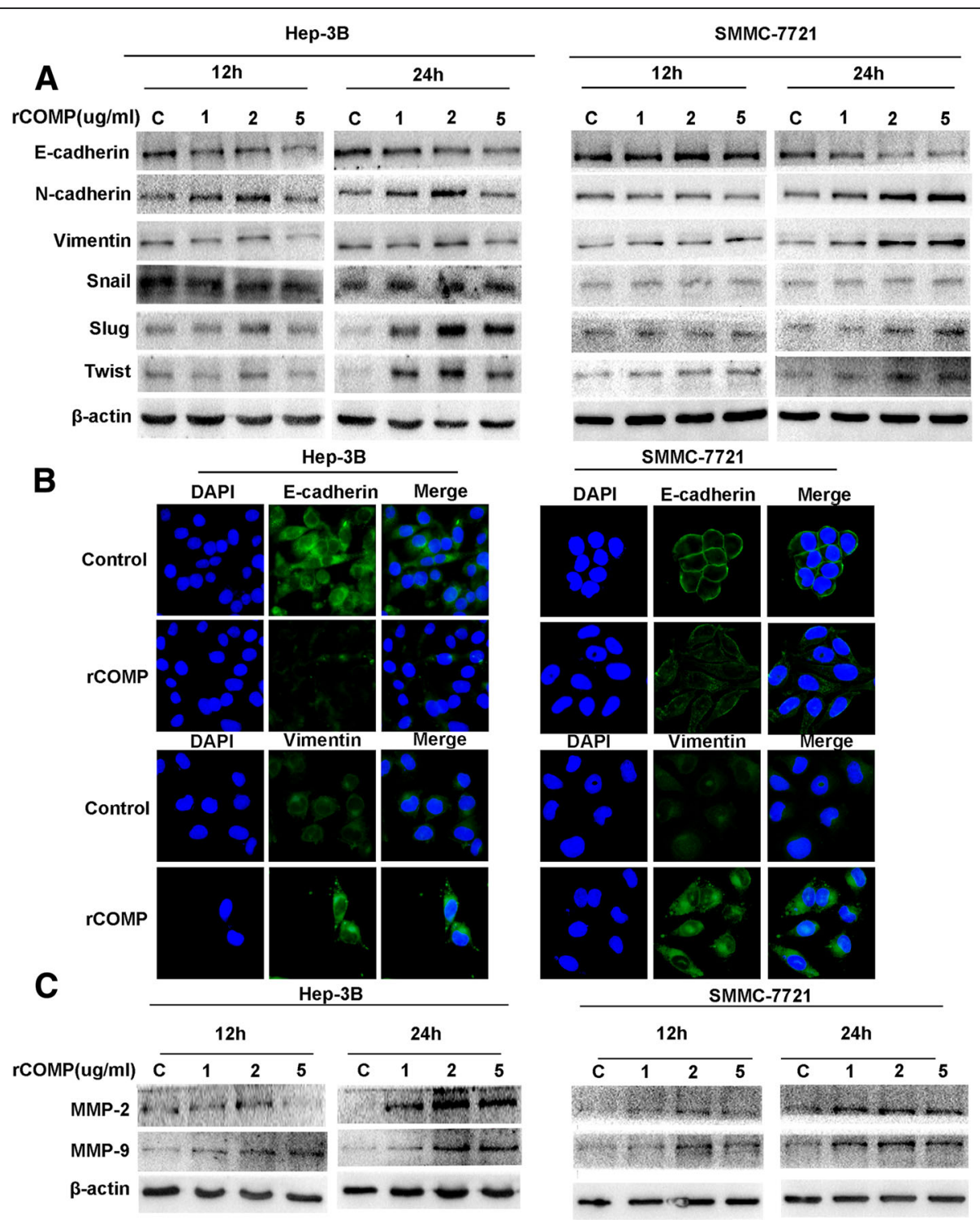

Fig. 4 COMP facilitates EMT and MMP-2/9 expression in HCC cells. a The expression of EMT markers and transcription factors were determined via Western blot after treatment with various concentrations of rCOMP (as indicated) for 12 and $24 \mathrm{~h}$. $\beta$-actin was used as a loading control. b The expression of E-cadherin (green) and vimentin (green) after treatment with rCOMP $(2 \mu \mathrm{g} / \mathrm{ml})$ were shown by immunofluorescence staining in both Hep-3B and SMMC-7721 cells. Representative images at $\times 400$ magnification are shown. $\mathbf{c}$ The levels of MMP-2/9 in HCC cells after treatment with various concentrations of rCOMP (as indicated) for 12 and $24 \mathrm{~h}$ as detected by Western blot analysis. $\beta$-actin was used as a loading control. Western blot and IF analysis were independently repeated for three times with similar results

activation to accelerate migration and invasion of $\mathrm{HCC}$ cells. The results showed that rCOMP treatment for $24 \mathrm{~h}$ significantly stimulated ERK and AKT phosphorylation in HCC cells in a dose-dependent manner without obvious changes of the total ERK and AKT expression levels, indicating the involvement of ERK and AKT phosphorylation in COMP-mediated promotion of migration and invasion potential of HCC cells (Fig. 5a). To confirm the role of MEK/ERK and PI3K/AKT pathways in proliferation and EMT process which regulated by COMP in HCC cells, the MEK inhibitor U0126 and PI3K inhibitor LY294002 were used. Interestingly, U0126 $(25 \mu \mathrm{M})$ and LY294002 $(20 \mu \mathrm{M})$ treatments in rCOMP-treated cells evidently inhibited the ability in proliferation than the rCOMPtreated controls, reversing changes caused by rCOMP $(P<0.05$, Fig. $5 \mathrm{~b}$ and Additional file 3: Figure S2A). Meanwhile, either U0126 or LY294002 treatment effectively suppressed migratory and invasive ability of rCOMP-treated cells $(P<0.05$, Fig. $5 \mathrm{c}$ and Additional file 3 : Figure S2B-C). Western blot results indicated that reduced E-cadherin expression in rCOMP-treated cells was recovered by U0126 or LY294002, whereas up-regulated mesenchymal 


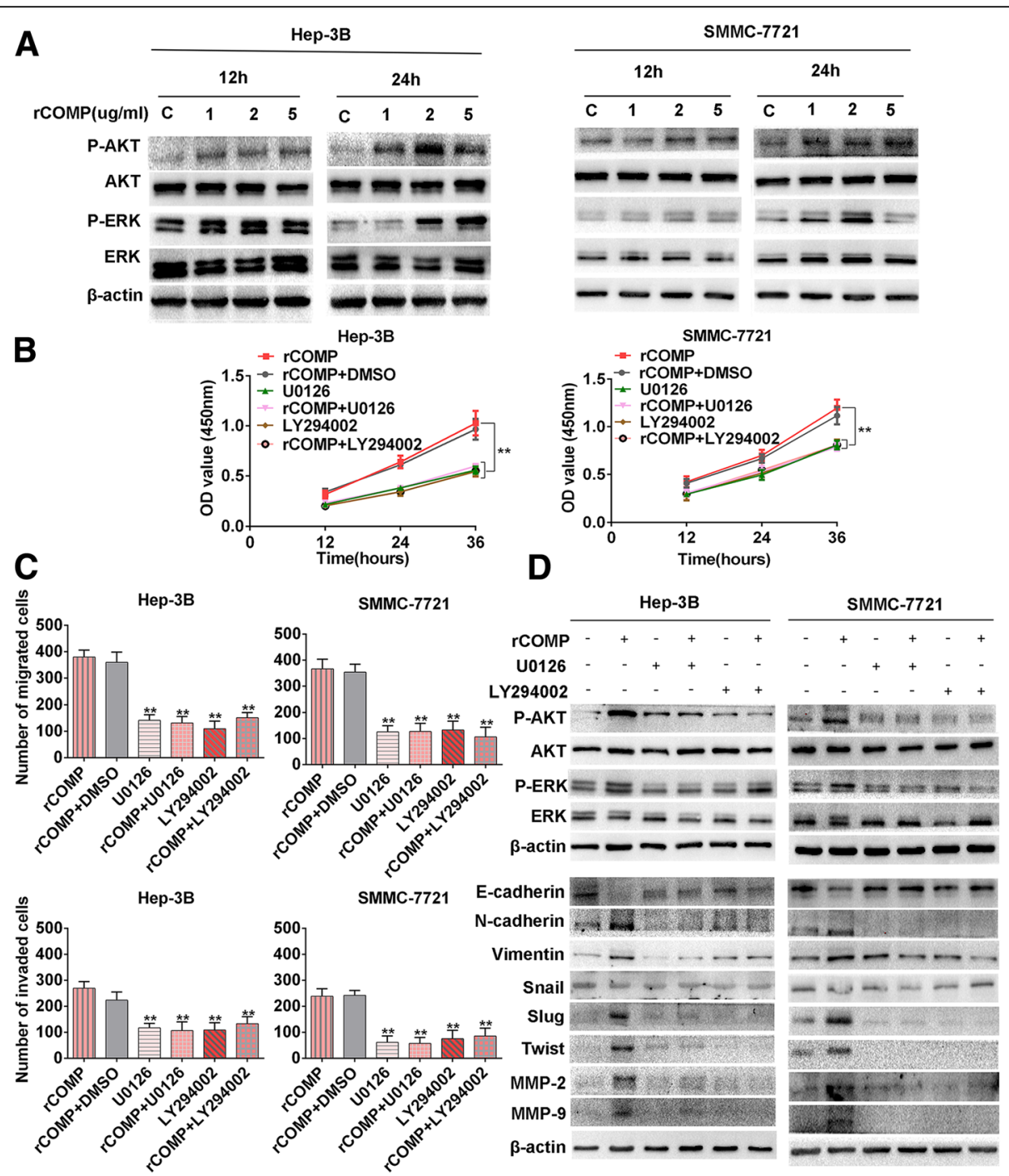

Fig. 5 COMP activates MEKJERK and PI3KNAKT pathway in HCC cells. a The levels of the indicated proteins in Hep-3B and SMMC-7721 after treatment with various concentrations of rCOMP (as indicated) as measured by Western blot. Total ERK and AKT were used as controls. $\mathbf{b}$ HCC

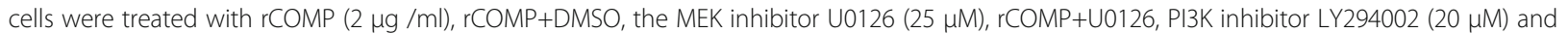
rCOMP+LY294002 for 12, 24 and 36 h, then the cell viability was evaluated using the CCK8 assay. The cell viability of every cell line with rCOMP + DMSO treatment was considered as control group. $n=$ three independent repeats. $P<0.05$ by ANOVA versus control. $\mathbf{c}$ HCC cells that were incubated with the indicated treatments were subjected to transwell migration and invasion assays. The number of migrated or invaded cells was counted in five different fields. $n=$ three independent repeats. $P<0.05$ by t test versus control. $\mathbf{d}$ The protein levels of the indicated factors after the indicated treatments were examined by Western blot. $\beta$-actin was used as a loading control. Western blot analysis was independently repeated for three times with similar results. $\left({ }^{*} P<0.05,{ }^{*} P<0.01\right)$

markers (N-cadherin and Vimentin), MMP-2/9, Slug and Twist were reduced by U0126 or LY294002 treatments (Fig. 5d). Collectively, we concluded that rCOMP could induce HCC progression by regulating the activity MEK/ERK and PI3K/AKT pathways.

\section{CD36 receptor mediated COMP induced MEK/ERK and PI3K/AKT activation}

Given the prior literatures about liver fibrosis suggesting that COMP induced fibrillary collagen-I deposition via CD36 receptor [4], we wonder if CD36 was related with
COMP in HCC. Knockdown of CD36 in Hep-3B and SMMC-7721 cells notably attenuated the rCOMP-induced promotion of cell proliferation and metastasis $(P<0.05$, Fig. 6a-c and Additional file 4: Figure S3A-C). In our in vitro analyses, we discovered the involvement and requirement of CD36 in biologic functions of COMP. Furthermore, we evaluated whether CD36 was involved in the process of COMP-induced HCC progression by establishing an orthotopic liver tumor model in nude mice. The results showed that CD36 knockdown attenuated the effect of rCOMP-induced promotion of tumor cell proliferation 


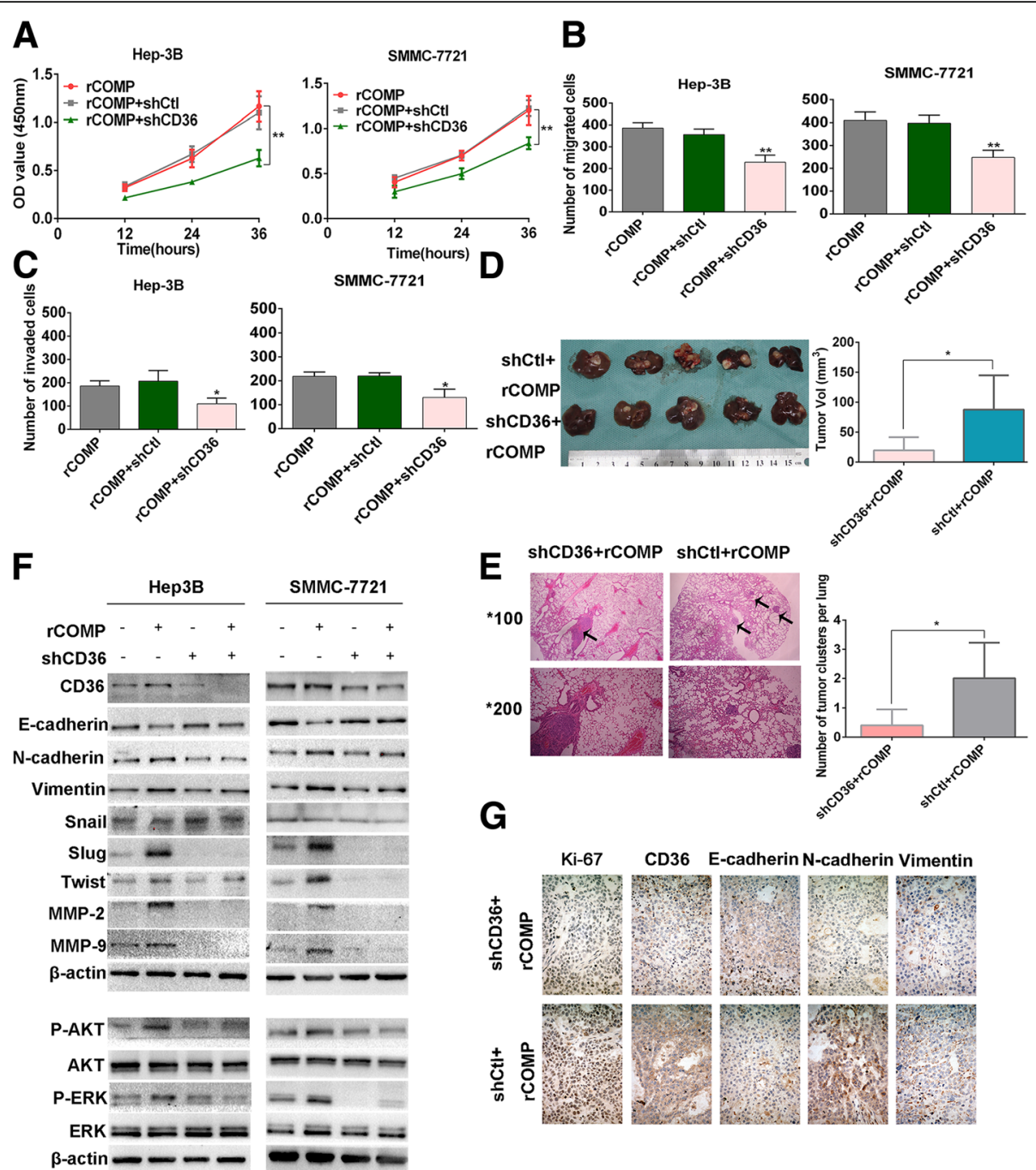

Fig. 6 CD36 mediates COMP induced MEK/ERK and PI3KNAKT pathways activation. a Cell viability after CD36 knockdown by shRNA was determined using CCK8 assay. The cell viability of every cell line with rCOMP+shCtl treatment was considered as control group. $\mathrm{n}=$ three independent repeats. $P<0.05$ by ANOVA versus control. $\mathbf{b}$ and $\mathbf{c}$ HCC cells after knockdown of CD36 were subjected with transwell migration and invasion assays. The number of migrated or invaded cells was counted in five different fields. $\mathrm{n}=$ three independent repeats. $P<0.05$ by $\mathrm{t}$ test versus control. $\mathbf{d}$ Photomicrographs were taken for orthotopic primary liver tumors formed by shCD36 + rCOMP or shCtl+rCOMP (left). Tumor volumes from each group $(n=5)$ were measured (right). $P<0.05$ by $t$ test versus shCtl+rCOMP. e Representative H\&E-stained sections of the lung tissues from the two groups were showed in the left. Magnification $\times 200$. A total of 10 random visual fields were chosen from different lung sections of each group, and pulmonary foci were quantified as the average number across the 10 visual fields per group (right). $P<0.05$ by $t$ test versus shCtl+rCOMP. $\mathbf{f}$ The expression of the indicated proteins in HCC cells after CD36 knockdown by shRNA compared with controls in Hep-3B and SMMC-7721 cells. CD36 knockdown was confirmed by Western blot. $\beta$-actin was used as a loading control. Western blot analysis was independently repeated for three times with similar results. $\mathbf{g}$ The expression of Ki67, CD36, E-cadherin, N-cadherin and vimentin in xenograft tumors from different groups were analyzed by immunohistochemistry. Representative images at $\times 200$ magnification are shown. $\left({ }^{*} P<0.05,{ }^{* *} P<0.01\right)$

and lung metastasis $(P<0.05$, Fig. $6 \mathrm{~d}$ and e). More importantly, the reduction of E-cadherin due to rCOMP treatment in two HCC cells could be recovered by CD36 knockdown (Fig. 6f). Likewise, knockdown of CD36 abrogated the effect of rCOMP-induced upregulation of $\mathrm{N}$-cadherin, Vimentin, Slug, Twist, MMP-2/9, P-ERK and P-AKT expression (Fig. 6f). These data demonstrated a mechanism by which COMP induced EMT by way of
CD36/ERK and CD36/AKT pathway. The IHC analysis of liver tumor displayed higher level of E-cadherin and lower levels of N-cadherin and Vimentin and Ki-67 in the group of CD36 knockdown (Fig. 6g), which was consistent with the results in Fig. 6f. Together, these results presented that functional significance of CD36 was involved in the COMP induced tumor grwoth and metastasis of HCC. Taken together, these data suggested a crucial role for COMP in 
regulation of EMT through control of CD36-ERK/AKT-Slug/Twist axis in HCC cells.

\section{COMP is one of HSCs-derived factors that drives HCC progression}

From clinical data, we concluded that COMP level was closely correlated with cirrhosis and HCC, therefore we designed experiments to detect whether the main source of COMP was from HSCs. The expression of COMP in activated hepatic stellate cell line LX2 and 5 HCC cell lines as well as one immortalized liver cell line LO2 were tested by Western blot analysis. The results showed that COMP was obviously highly expressed in LX2 cells (Fig. 7a). Besides, we also found that the level of COMP in cell culture supernatant as detected by ELISA was the highest in LX2 cells $(P<0.05$, Fig. 7a), which was consistent with the findings of Western blot. These results suggested that COMP might be mainly secreted by activated hepatic stellate cells. Next, more experiments were performed to fully explore the biological significance of HSCs-derived COMP in HCC. Firstly, LX2 activation maker $\alpha$-SMA was confirmed by IF (Fig. 7b). Knockdown of COMP by two different siRNAs in LX2 consistently inhibited the expression and secretion of COMP $(P<0.05$, Fig. $7 \mathrm{c})$. Conditioned medium $(\mathrm{CM})$ of LX2 cells with or without COMP knockdown were cocultured with Hep-3B or SMMC-7721 cells for $24 \mathrm{~h}$. These results indicated that knockdown of COMP significantly attenuated the tumor promoting effects of LX2 cells on HCC cells $(P<0.05$, Additional file 5: Figure S4A-C). Then, we detected HCC cells with molecular markers of EMT. E-cadherin expression was obviously up-regulated, whereas mesenchymal markers such as N-cadherin, Vimentin and EMT regulators Slug and Twist were significantly down-regulated in $\mathrm{HCC}$ cells, which were treated with CM of COMP knockdown LX2 cells (Fig. 7d). Besides, the CM of COMP knockdown LX2 cells reduced MMP-2 and MMP-9 levels compared to the control (Fig. 7d). Moreover, the phosphorylation of ERK and AKT were significantly decreased in the CM of COMP knockdown LX2 treated HCC cells (Fig. 7d). These data indicated that COMP was one of HSCs derived factors and played an important role in controlling HCC cell proliferation and metastasis. In conclusion, HSCs-derived COMP promoted HCC progression by activating MEK/ERK and PI3K/AKT signaling pathway in a CD36-dependent manner (Fig. 7e).

\section{Discussion}

The process of viral hepatitis-cirrhosis-HCC is the main epidemiological development path of $\mathrm{HCC}$ in world. Most (80\%) of HCCs originate from severe liver fibrosis or cirrhosis [2]. Increased hepatic matrix stiffness results from the deposition and cross-linking of large amounts of matrix proteins, not only extensively occurs in most solid tumors but also promotes cell growth, motility, proliferation, metabolism and tumor metastasis [25-28]. HSCs, multifunctional hepatic stromal cells, differentiate into fibrogenic, hyperproliferative, contractile, and migrating myofibroblasts in chronic liver disease. In fibrosis and cirrhosis, these myofibroblastic HSCs are the culprits for many abnormal ECM deposits. Several publications revealed that COMP was involved with process of cirrhosis and HCC progression. However, the exact sources and functions of COMP still remain to be fully elucidated in HCC-related literature. In this regard, we demonstrated for the first time that COMP was mainly derived from activated HSCs and dose-dependently promoted HCC growth and metastasis. COMP induced CD36-dependent activation of MEK/ERK and PI3K/ $\mathrm{AKT}$, and a panel of tumor-promoting factors, including EMT makers, MMP-2/9, Slug and Twist, so as to promote its tumor-promoting effects. Our data illustrated a novel signal transduction pathway for metastatic growth of HCC (Fig. 7e).

In the present study, we identified that the level of COMP was frequently elevated in the serum of HCC patients. Patients with high level of serum COMP showed more unfavorable disease parameters such as higher incidence of vascular invasion and tumor recurrence. Additionally, HCC patients with high serum COMP level had a poorer prognosis than those with low serum COMP level. These results suggest that COMP may play important oncogenic roles in HCC progression which is consistent with previous report [5]. Cell proliferation and migration have been reported to involve various growth factors, which bind to their receptors on the cell surface to activate downstream signaling pathways, leading to cytoskeletal reorganization and stimulation of cellular motility machinery [29]. Here the oncogenic effects of COMP on HCC pathogenesis were directly demonstrated in the current study by both in vitro and in vivo functional assays. Our finding indicated that either exogenous COMP treatment or HSCs coculture stimulated malignant behaviors, such as proliferation, invasion and migration of HCC cells. In both subcutaneous xenografts and the tail vein injection model, rCOMP group generated bigger primary tumors and more lung metastatic foci, indicating that COMP enhanced aggressive and metastatic properties of HCC. Besides, COMP did not affect cell apoptosis of HCC cell lines (data not shown). To our knowledge, this is the first report that COMP acts as a driver of HCC proliferation and metastasis.

The acquisition of invasive capabilities includes degradation of the cell matrix and turnover of cell-cell adhesion junctions [30]. Down-regulation of E-cadherin is a significant hallmark of EMT. In our study, rCOMP treatment in HCC cells led to the up-regulation of Slug/ 


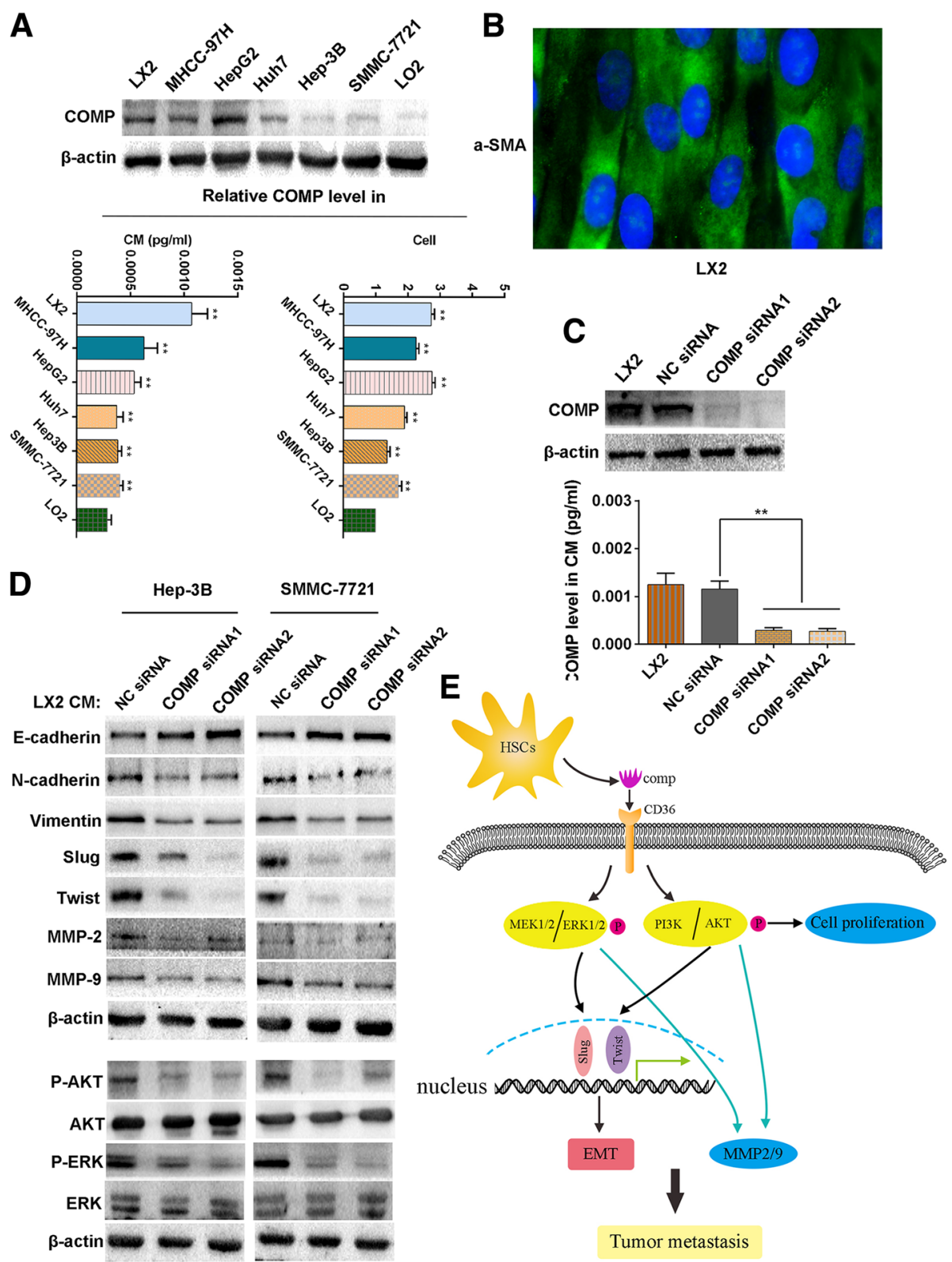

Fig. 7 LX2 cells-derived COMP drives tumor progression. a COMP concentrations (detected by ELISA) in conditioned media (CM) and COMP expression (detected by Western blot) in 5 HCC cell lines and hepatocytes LO2 and activated hepatic stellate cell LX2. LO2 was used as a negative control. $n=$ three independent repeats. $P<0.05$ by $\mathrm{t}$ test versus LO2. $\mathbf{b}$ The marker of activated hepatic stellate cells a-SMA was confirmed using IF. Representative images at $\times 400$ magnification are shown. $\mathbf{c}$ The level of COMP in the LX2 and CM was confirmed by Western blot and ELISA after knockdown by siRNAs. The NC siRNA was used as control. $\mathrm{n}=$ three independent repeats. $P<0.05$ by $\mathrm{t}$ test versus control. $\mathbf{d}$ The expression of the indicated proteins in HCC cells after co-cultured with LX2 cells after knockdown of COMP were examined by Western blot. $\beta$-actin was used as a loading control. Western blot analysis was independently repeated for three times with similar results. e The proposed model by which HSCs-derived COMP promotes HCC progression by activating MEK/ERK and PI3KJAKT signaling pathway via a CD36-dependent manner. $\left.{ }^{*} P<0.05,{ }^{* *} P<0.01\right)$

Twist, N-cadherin and Vimentin, and repressed expression of E-cadherin and thereby triggered EMT. It has been demonstrated that MMP-2/9 can regulate the degradation of the extracellular matrix (ECM), which plays an important role in cancer metastasis [31]. Our study also observed that COMP advanced the expression level of MMP-2/9. Therefore, this study clearly demonstrates that COMP functions as a metastasis inducer in HCC through promoting EMT via regulation of Slug/Twist and inducting matrix degradation.

Both the MER/ERK and PI3K/AKT signaling pathway are involved in the regulation of tumor cell growth, 
metabolism, proliferation, as well as metastasis and are frequently proved to be active in many different types of cancer [32]. A recent report indicated that COMP could promote the process of liver fibrosis through MEK/ERK signaling pathway [4]. In our research, both the phosphorylation level of ERK and AKT were dramatically induced by rCOMP. EMT markers, MMP-2/9 and Slug/ Twist are well-known downstream regulators of MEK/ ERK and PI3K/AKT signaling pathways. Therefore, as expected, the expression of these proteins were suppressed when ERK or AKT pathway were inhibited. Besides, a crosstalk between AKT and ERK signaling pathways could be observed in the results, which was consistent with other studies [33, 34]. Taken together, our data confirmed the pro-proliferative and pro-invasive effects of COMP in HCC.

It has been shown that CD36 is up-regulated in human HCCs and involved in EMT [10]. Thus, we found that knockdown of CD36 attenuated rCOMP-induced proliferation, migration and invasion of HCC cells. Moreover, down-regulation of CD36 led to severe inhibition of rCOMP-induced tumor growth and lung metastasis of $\mathrm{HCC}$ in vivo. Therefore, we conclude that CD36 is essentially required for COMP/ERK and COMP/AKT induced HCC progression. To our knowledge, this is the first report that COMP connects with CD36 to stimulate HCC metastasis, in addition to tumor proliferation and growth. However, further studies will be necessary to expand our knowledge of the relationship between COMP and CD36.

In HCC, metastatic microenvironment is consisted of hepatoma cells, activated hepatic stellate cells, extracellular matrix, and their secreted or released various cytokines to regulate tumor metastasis. These cells and matrix components interact in the presence of various cytokines and participate in the process of hepatocellular carcinoma metastasis [35]. It has been increasingly recognized that activated HSCs act as important contributors to tumor progression [36]. Identifying the critical pathway involved in this crosstalk could potentially improve the efficiency of treatment. In this study, we detected the expression of COMP in activated HSCs LX2 and several HCC cells and hepatocytes LO2. The result indicated that the level of COMP in LX2 cells and its supernatants was the highest. These data suggested that COMP might be primarily secreted by HSCs. To support this hypothesis, we further established hepatocytes-HSCs crosstalk to analyzing the role of COMP in HCC microenvironment. Interestingly, the MEK/ERK and PI3K/AKT pathways were activated in HCC cells by coculture of activated HSCs and hepatoma cells, along with the upregulation of their downstream factors. Furthermore, above factors were deregulated in $\mathrm{Hep}-3 \mathrm{~B}$ and SMMC-7721 cells respond to the coculture with LX2 after knockdown of COMP. Thus, the data suggest that COMP plays an important role in the dynamic interactions between cancer cells and activated HSCs in the progression of hepatocellular carcinoma.

\section{Conclusions}

We uncovered a novel mechanism by which HSCs-derived COMP was frequently elevated in serum samples of HCC patients and played a very important role in HCC development and progression by activating ERK and AKT signaling pathways via a CD36-dependent manner. A better understanding of the oncogenic mechanisms of COMP in HCC may contribute to identify a promising biomarker in HCC diagnosis and a novel therapeutic strategy in $\mathrm{HCC}$ treatment.

\section{Additional files}

Additional file 1: Table S1. Association between clinicopathological parameters and serum COMP level in primary hepatocellular carcinoma. (DOCX $17 \mathrm{~kb}$ )

Additional file 2: Figure S1. rCOMP treatment up-regulates the levels of Slug and Twist mRNA in HCC cells. The relative mRNA levels of Slug and Twist were up-regulated by rCOMP treatment both in Hep3B and SMMC-7721 cells. Each experiment was repeated at least three times. ${ }^{*} P<0.01$ by $\mathrm{t}$ test versus control. (TIF $212 \mathrm{~kb}$ )

Additional file 3: Figure S2. COMP facilitates growth and metastasis of HCC cells via MEKJERK and PI3KVAKT pathways. A) The plate colony formation assay was used to assess the growth of HCC cells with the indicated treatments and the number of foci from three independent experiments were calculated and compared. $P<0.05$ by t test versus rCOMP+DMSO. B) Hep-3B and SMMC-7721 cells were treated with the indicated treatments for $24 \mathrm{~h}$, the effect of rCOMP on cell migration was measured by wound-healing assay. The wound closure (\%) of HCC cells in each concentration of rCOMP was calculated. Representative images at $\times 400$ magnification are shown. $n=$ three independent repeats, $P<0.05$ by $t$ test versus rCOMP+DMSO. C) The representative images of transwell migration and invasion assays. Original magnification $\times 200$. Each experiment was carried out in triplicate wells and repeated at least three times. ( $\left.{ }^{*} P<0.05,{ }^{*} P<0.01\right)$. (TIF $3192 \mathrm{~kb}$ )

Additional file 4: Figure S3. CD36 is required for the oncogenic function of COMP. A) The plate colony formation assay was used to assess the growth of HCC cells after knockdown of CD36 and the number of foci from three independent experiments were calculated and compared. $P<0.05$ by t test versus $r C O M P+$ shCtl. B) HCC cells after knockdown of CD36 were subjected to wound-healing assay. The wound closure (\%) of HCC cells in each concentration of rCOMP was calculated. Representative images at $\times 400$ magnification are shown. $n=$ three independent repeats, $P<0.05$ by t test versus rCOMP+shCtl. C) The representative images of transwell migration and invasion assays at $\times 200$ magnification are shown. Each experiment of wound-healing assay and transwell assay was carried out in triplicate wells and repeated at least three times. $\left({ }^{*} P<0.05,{ }^{* *} P<0.01\right.$ ). (TIF $2580 \mathrm{~kb}$ )

Additional file 5: Figure S4. LX2 cells-derived COMP promotes tumor progression. A) The plate colony formation assay was used to assess the growth of HCC cells after cocultured with LX2 cells and the number of foci from three independent experiments were calculated and compared. $P<0.05$ by t test versus NC siRNA. B) HCC cells after cocultured with LX2 cells were subjected to wound-healing assay. The wound closure (\%) of HCC cells was calculated. Representative images at $\times 400$ magnification are shown. $n=$ three independent repeats, $P<0.05$ by $t$ test versus NC siRNA. C) Transwell migration and invasion assays of HCC cells after cocultured with LX2 cells. The number of migrated or invaded cells was counted in five different fields. Representative images at $\times 200$ magnification are shown. Each experiment of wound-healing assay and transwell assay 
was carried out in triplicate wells and repeated at least three times. $P<0.05$ by $t$ test versus NC siRNA. $\left({ }^{*} P<0.05\right.$, ${ }^{* *} P<0.01$ ). (TIF $3501 \mathrm{~kb}$ )

\section{Abbreviations}

CM: Conditioned medium; COMP: Cartilage oligomeric matrix protein; ELISA: Enzyme-linked immunosorbent assay; EMT: Epithelial to mesenchymal transition; HBV: Hepatitis B virus; HCC: Hepatocellular carcinoma;

HSCs: Human hepatic stellate cells; IHC: Immunohistochemistry; MMP: Matrix metalloproteinase; rCOMP: recombinant human COMP protein; ROC: Receiver operating characteristic

\section{Acknowledgements}

We thank Dr. Wei Chen (Children' Hospital of Xi'an, China) for assistance of the manuscript.

\section{Funding}

This work was supported by grants from National Natural Science Foundation of China (81773123, 81572847), Innovation Capacity Support Plan in Shaanxi Province of China (2018KJXX-045) and the Fundamental Research Funds for the Central Universities (7 N010011015).

\section{Availability of data and materials}

All data generated or analyzed during this study are included either in this article or in the supplementary information files.

\section{Authors' contributions}

QL and KT conceived and designed the experiments; QL, CW, YW, KS and ZL performed the experiments; LW and TS analyzed the data; YY contributed reagents/materials/analysis tools; QL and KT wrote the paper. All authors read and approved the final manuscript.

\section{Ethics approval and consent to participate}

All procedures performed in studies involving human participants were in accordance with the ethical standards of the Research Ethics Committee of The First Affiliated Hospital of Xi'an Jiaotong University and with the 1964 Helsinki declaration and its later amendments. ALL written informed consent to participate in the study was obtained from HCC patients for samples to be collected from them.

\section{Consent for publication}

Not applicable.

\section{Competing interests}

The authors declare that they have no competing interests.

\section{Publisher's Note}

Springer Nature remains neutral with regard to jurisdictional claims in published maps and institutional affiliations.

\section{Received: 21 June 2018 Accepted: 12 September 2018}

\section{Published online: 19 September 2018}

\section{References}

1. Allemani C, Weir HK, Carreira H, Harewood R, Spika D, Wang XS, Bannon F, Ahn JV, Johnson CJ, Bonaventure A, et al. Global surveillance of cancer survival 1995-2009: analysis of individual data for 25,676,887 patients from 279 population-based registries in 67 countries (CONCORD-2). Lancet. 2015; 385(9972):977-1010.

2. Fattovich G, Stroffolini T, Zagni I, Donato F. Hepatocellular carcinoma in cirrhosis: incidence and risk factors. Gastroenterology. 2004;127(5 Suppl 1): S35-50.

3. Vuga $\amalg$, Milosevic J, Pandit K, Ben-Yehudah A, Chu Y, Richards T, Sciurba J, Myerburg M, Zhang $Y$, Parwani AV, et al. Cartilage oligomeric matrix protein in idiopathic pulmonary fibrosis. PLoS One. 2013;8(12):e83120.

4. Magdaleno F, Arriazu E, Ruiz de Galarreta M, Chen Y, Ge X, Conde de la Rosa L, Nieto N. Cartilage oligomeric matrix protein participates in the pathogenesis of liver fibrosis. J Hepatol. 2016;65(5):963-71.

5. Norman GL, Gatselis NK, Shums Z, Liaskos C, Bogdanos DP, Koukoulis GK, Dalekos GN. Cartilage oligomeric matrix protein: a novel non-invasive marker for assessing cirrhosis and risk of hepatocellular carcinoma. World $\rfloor$ Hepatol. 2015;7(14):1875-83.

6. Xiao Y, Kleeff J, Guo J, Gazdhar A, Liao Q, Di Cesare PE, Buchler MW, Friess $\mathrm{H}$. Cartilage oligomeric matrix protein expression in hepatocellular carcinoma and the cirrhotic liver. J Gastroenterol Hepatol. 2004;19(3):296-302.

7. Englund E, Bartoschek M, Reitsma B, Jacobsson L, Escudero-Esparza A, Orimo A, Leandersson K, Hagerling C, Aspberg A, Storm P, et al. Cartilage oligomeric matrix protein contributes to the development and metastasis of breast cancer. Oncogene. 2016;35(43):5585-96.

8. Liu TT, Liu XS, Zhang M, Liu XN, Zhu FX, Zhu FM, Ouyang SW, Li SB, Song $\mathrm{CL}$, Sun HM, et al. Cartilage oligomeric matrix protein is a prognostic factor and biomarker of colon cancer and promotes cell proliferation by activating the Akt pathway. J Cancer Res Clin Oncol. 2018;144(6):1049-63.

9. Englund E, Canesin G, Papadakos KS, Vishnu N, Persson E, Reitsma B, Anand A, Jacobsson L, Helczynski L, Mulder H, et al. Cartilage oligomeric matrix protein promotes prostate cancer progression by enhancing invasion and disrupting intracellular calcium homeostasis. Oncotarget. 2017;8(58):98298-311.

10. Nath A, Li I, Roberts LR, Chan C. Elevated free fatty acid uptake via CD36 promotes epithelial-mesenchymal transition in hepatocellular carcinoma. Sci Rep. 2015;5:14752.

11. Nakamura S, Muro H, Suzuki S, Sakaguchi T, Konno H, Baba S, Syed AS. Immunohistochemical studies on endothelial cell phenotype in hepatocellular carcinoma. Hepatology. 1997;26(2):407-15.

12. Dou C, Liu Z, Xu M, Jia Y, Wang Y, Li Q, Yang W, Zheng X, Tu K, Liu Q. miR187-3p inhibits the metastasis and epithelial-mesenchymal transition of hepatocellular carcinoma by targeting S100A4. Cancer Lett. 2016;381(2): $380-90$.

13. Xu Q, Liu X, Liu Z, Zhou Z, Wang Y, Tu J, Li L, Bao H, Yang L, Tu K. MicroRNA-1296 inhibits metastasis and epithelial-mesenchymal transition of hepatocellular carcinoma by targeting SRPK1-mediated PI3K/AKT pathway. Mol Cancer. 2017;16(1):103.

14. Wang Y, Liu Z, Yao B, Li Q, Wang L, Wang C, Dou C, Xu M, Liu Q, Tu K. Long non-coding RNA CASC2 suppresses epithelial-mesenchymal transition of hepatocellular carcinoma cells through CASC2/miR-367/FBXW7 axis. Mol Cancer. 2017;16(1):123

15. Ma J, Zeng S, Zhang Y, Deng G, Qu Y, Guo C, Yin L, Han Y, Cai C, Li Y, et al. BMP4 promotes oxaliplatin resistance by an induction of epithelialmesenchymal transition via MEK1/ERK/ELK1 signaling in hepatocellular carcinoma. Cancer Lett. 2017:411:117-29.

16. Zhang Y, Zeng S, Ma J, Deng G, Qu Y, Guo C, Shen H. Nestin overexpression in hepatocellular carcinoma associates with epithelial-mesenchymal transition and chemoresistance. J Exp Clin Cancer Res. 2016;35(1):111.

17. Lamouille $S, X u$ J, Derynck R. Molecular mechanisms of epithelialmesenchymal transition. Nat Rev Mol Cell Biol. 2014;15(3):178-96.

18. Kuijpers MJ, de Witt S, Nergiz-Unal R, van Kruchten R, Korporaal SJ, Verhamme P, Febbraio M, Tjwa M, Voshol PJ, Hoylaerts MF, et al. Supporting roles of platelet thrombospondin-1 and CD36 in thrombus formation on collagen. Arterioscler Thromb Vasc Biol. 2014;34(6):1187-92.

19. Dou C, Liu Z, Tu K, Zhang H, Chen C, Yaqoob U, Wang Y, Wen J, van Deursen J, Sicard D, et al. P300 acetyltransferase mediates stiffness-induced activation of hepatic stellate cells into tumor-promoting Myofibroblasts. Gastroenterology. 2018;154(8):2209-21.

20. Nair AB, Jacob S. A simple practice guide for dose conversion between animals and human. J Basic Clin Pharm. 2016;7(2):27-31.

21. Zhang J, Li Z, Liu L, Wang Q, Li S, Chen D, Hu Z, Yu T, Ding J, Li J, et al. Long noncoding RNA TSLNC8 is a tumor suppressor that inactivates the interleukin-6/STAT3 signaling pathway. Hepatology. 2018;67(1):171-87.

22. Nagalingam A, Arbiser JL, Bonner MY, Saxena NK, Sharma D. Honokiol activates AMP-activated protein kinase in breast cancer cells via an LKB1dependent pathway and inhibits breast carcinogenesis. Breast Cancer Res. 2012;14(1):R35.

23. Chen H, Zhu G, Li Y, Padia RN, Dong Z, Pan ZK, Liu K, Huang S. Extracellular signal-regulated kinase signaling pathway regulates breast cancer cell migration by maintaining slug expression. Cancer Res. 2009;69(24):9228-35.

24. Pal I, Mandal M. PI3K and Akt as molecular targets for cancer therapy: current clinical outcomes. Acta Pharmacol Sin. 2012:33(12):1441-58.

25. Ulrich TA, de Juan Pardo EM, Kumar S. The mechanical rigidity of the extracellular matrix regulates the structure, motility, and proliferation of glioma cells. Cancer Res. 2009;69(10):4167-74.

26. Tilghman RW, Blais EM, Cowan CR, Sherman NE, Grigera PR, Jeffery ED, Fox JW, Blackman BR, Tschumperlin DJ, Papin JA, et al. Matrix rigidity regulates 
cancer cell growth by modulating cellular metabolism and protein synthesis. PLoS One. 2012;7(5):e37231.

27. Levental KR, Yu H, Kass L, Lakins JN, Egeblad M, Erler JT, Fong SF, Csiszar K, Giaccia A, Weninger W, et al. Matrix crosslinking forces tumor progression by enhancing integrin signaling. Cell. 2009;139(5):891-906.

28. Schrader J, Gordon-Walker TT, Aucott RL, van Deemter M, Quaas A, Walsh S, Benten D, Forbes SJ, Wells RG, Iredale JP. Matrix stiffness modulates proliferation, chemotherapeutic response, and dormancy in hepatocellular carcinoma cells. Hepatology. 2011;53(4):1192-205.

29. Wang S, Yu S, Shi W, Ge L, Yu X, Fan J, Zhang J. Curcumin inhibits the migration and invasion of mouse hepatoma Hca-F cells through downregulating caveolin-1 expression and epidermal growth factor receptor signaling. IUBMB Life. 2011;63(9):775-82.

30. Reichl P, Dengler M, van Zijl F, Huber H, Fuhrlinger G, Reichel C, Sieghart W, Peck-Radosavljevic M, Grubinger M, Mikulits W. Axl activates autocrine transforming growth factor-beta signaling in hepatocellular carcinoma. Hepatology. 2015;61(3):930-41.

31. Qian L, Liu Y, Xu Y, Ji W, Wu Q, Liu Y, Gao Q, Su C. Matrine derivative WM130 inhibits hepatocellular carcinoma by suppressing EGFR/ERK/MMP-2 and PTEN/AKT signaling pathways. Cancer Lett. 2015;368(1):126-34.

32. Jiang L, Yan Q, Fang S, Liu M, Li Y, Yuan YF, Li Y, Zhu Y, Qi J, Yang X, et al. Calcium-binding protein 39 promotes hepatocellular carcinoma growth and metastasis by activating extracellular signal-regulated kinase signaling pathway. Hepatology. 2017;66(5):1529-45.

33. Aksamitiene E, Kholodenko BN, Kolch W, Hoek JB, Kiyatkin A. PI3K/Aktsensitive MEK-independent compensatory circuit of ERK activation in ERpositive PI3K-mutant T47D breast cancer cells. Cell Signal. 2010;22(9):1369-78.

34. Niba ET, Nagaya H, Kanno T, Tsuchiya A, Gotoh A, Tabata C, Kuribayashi K, Nakano T, Nishizaki T. Crosstalk between PI3 kinase/PDK1/Akt/Rac1 and Ras/ Raf/MEK/ERK pathways downstream PDGF receptor. Cell Physiol Biochem. 2013;31(6):905-13.

35. Kang $N$, Gores $G J$, Shah VH. Hepatic stellate cells: partners in crime for liver metastases? Hepatology. 2011;54(2):707-13.

36. Waghray M, Yalamanchili M, Dziubinski M, Zeinali M, Erkkinen M, Yang H, Schradle KA, Urs S, Pasca Di Magliano M, Welling TH, et al. GM-CSF mediates mesenchymal-epithelial cross-talk in pancreatic Cancer. Cancer discovery. 2016;6(8):886-99.

Ready to submit your research? Choose BMC and benefit from:

- fast, convenient online submission

- thorough peer review by experienced researchers in your field

- rapid publication on acceptance

- support for research data, including large and complex data types

- gold Open Access which fosters wider collaboration and increased citations

- maximum visibility for your research: over $100 \mathrm{M}$ website views per year

At $\mathrm{BMC}$, research is always in progress.

Learn more biomedcentral.com/submissions 